\title{
Effect of Artificial Saliva Contamination on Bond Strength to Pulp Chamber Dentin
}

Hale Arı

Nazmiye Dönmez ${ }^{b}$

Sema Bellic

\section{ABSTRACT}

Objectives: The purpose of this in vitro study was to evaluate the effect of artificial saliva contamination on microtensile bond strength to pulp chamber dentin.

Methods: Clearfil SE Bond (SEB) (Kuraray, JAPAN) adhesive system and Clearfil Photo Posterior (CPP) (Kuraray, JAPAN) composite resin were used. Twenty extracted caries-free human molar teeth were randomly distributed into four groups. Apart from a control group without contamination (Group 1), primed dentin surfaces were contaminated with artificial saliva (10 s), rinsed, dried, reprimed and bonded (Group 2), coated with adhesive, contaminated with artificial saliva, rinsed, dried, bonding procedures were repeated (Group 3), coated with adhesive, light cured, contaminated with saliva, rinsed, dried, treated with SE primer (SEP) and SEB (Group 4).

After $24 \mathrm{hrs}$, the teeth were prepared for microtensile bond testing and tensile bond strength was measured ( $1 \mathrm{~mm} / \mathrm{min}$ ). The data was calculated as MPa and analyzed using one-way ANOVA and Duncan test $(\mathrm{P}<.05)$.

Results: The results indicated that Group 2 showed lowest bond strength when compared to the others $(P<.05)$. No statistically significant difference was found between Groups 3 and $4(P>.05)$.

Conclusions: It was concluded that contamination during priming procedure has a negative effect on bond strength $(P<.05)$. Although contamination of the uncured adhesive was not critical in this study ( $P>.05$ ) any kind of contamination of the bonding area should, in principle, be avoided. (Eur J Dent 2008;2:86-90)

Key words: Saliva contamination; Self-etch adhesive; Bond strength.

assoc. Prof., Selcuk University, Faculty of Dentistry, Department of Endodontics, Konya, Turkey.

b Specialist in Oral Health Center in Bahcelievler, Istanbul, Turkey

Professor, Selcuk University, Faculty of Dentistry, Department of Endodontics, Konya, Turkey.

- Corresponding author: Dr. Nazmiye DONMEZ Bahcelievler Agiz ve Dis Sagligi Merkezi Sirinevler mh. Eski Londra asfalti Adnan Kahveci Bulvari Bahcelievler/ Istanbul Phone: + 902124415312

E-mail: nazmiyedonmezahotmail.com

\section{INTRODUCTION}

The increasing popularity of dental composites has drawn attention to the importance of moisture and contamination control. The difficulty of achieving moisture control is a common problem encountered in restorative dentistry. For decades, it has been a clinically accepted requirement, in case of salivary contamination, to re-prepare enamel and dentin prior to proceeding with the adhesive technique. ${ }^{1}$ For many years the use of a rubber dam for proper isolation and prevention of cavity contamination have been recommended. 
The mandate is, sometimes rubber dam isolation is impossible especially in posterior region during endodontic therapy of loss of sound tooth structure. ${ }^{1}$

There are many factors that may affect the bond strength between restorative material and tooth structure such as the intrinsic properties of the prepared dentin, variation in dentin depth, tubule diameter, morphology, calcium concentration, dentinal fluid, saliva contamination, gingival fluids, blood and organic biofilms. ${ }^{2-4}$ The fact that this restorative treatment to do under the oral conditions like moisture and saliva presence was taking to apenda to consideration affect on the bond strength of saliva and moisture contamination. Several authors reported effects of saliva and moisture contamination on bond strength. ${ }^{5-9}$

In order to obtain successful adhesion between resin composite and tooth structure, it is necessary that the adhesive substrate should not be contaminated with fluids, such as saliva, blood, plasma, saline or debris from temporary cements. Sites at or near the gingival margins can be easily contaminated with saliva or gingival crevicular fluid. Dentin bonding systems have been shown to be sensitive to contamination with saliva and plasma. ${ }^{10}$ Both immediate and long term bond strengths under intra oral conditions are crucial for good clinical performance of adhesive restorations therefore there is a need to evaluate the effect of contamination on the effect of bond strength of this adhesive systems.

In case it happens, which steps are necessary to be repeated should be known. Therefore, the purpose of this study was to examine the effect of artificial saliva contamination on the microtensile bond strength (MTBS) of a self-etching primer adhesive system to pulp chamber dentin.

\section{MATERIALS AND METHODS}

The materials, the ingredients of the materials and application procedures were given in Table 1. An artificial saliva (the salts were dissolved in $900 \mathrm{ml} \mathrm{H} 20$ - adjusted to $\mathrm{pH}=7$, using $\mathrm{KOH}$ - diluted to $1 \mathrm{~L}$ and then cholesterol esterase enzyme was added) was substituted for human saliva. The ingredients of the artificial saliva ${ }^{11}$ were presented in Table 2.

Twelve caries-free human molars extracted recently were used. After removal of calculus and soft-tissue debris, the access cavities were opened, the pulp tissues were carefully removed and the crowns were separated at the cementoenamel junction using a high-speed bur under water-cooling. Twelve teeth were then randomly distributed into four groups of three teeth each and were prepared as follows:

Group 1 (Control): Clearfil SE Primer (SEP) and SE Bond (SEB) (Kuraray Co., Ltd, JAPAN) were applied to the pulp chamber dentin according to the manufacturer's instructions, and then the pulp chamber dentin was filled with a resin restorative material Clearfil Photo Posterior (CPP) (Kuraray Co., Ltd, JAPAN) incrementally. Each increment was cured using a curing light for 40 seconds (Hilux, Benlioglu,Turkiye).

Group 2: After applying SEP and drying for 10s., dentin surfaces were contaminated with artificial saliva for 10s, rinsed, dried, re-primed and dried for $10 \mathrm{~s}$. SEB was re- applied, light cured for $10 \mathrm{~s}$. and restored with CPP.

Group 3: Cavity surfaces were primed and dried. Before curing the SEB bonding resin, dentin surfaces were contaminated with artificial saliva, rinsed and dried. Bonding procedures were repeated and the teeth were restored with CPP.

Group 4: The cavity surfaces were primed and bonded. After light curing the bonding resin, dentin surfaces were contaminated with artificial saliva, rinsed, dried and re-prepared with SEB. The cavities were then restored with CPP.

The filled specimens were kept at $37^{\circ} \mathrm{C}$ water for $24 \mathrm{hrs}$. The specimens were fixed to a Plexiglas block with sticky wax and serial cross-sections 1 $\mathrm{mm}$ thick from CEJ to apex was obtained using a Isomet saw (Buehler Ltd., Lake Bluff, IL). The non-trimming method ${ }^{12}$ was used to obtain sample sticks with cross-sectional areas of 1

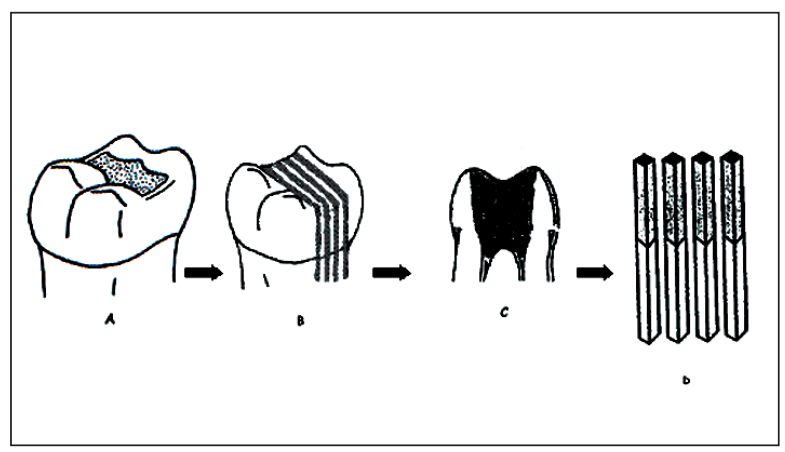

Figure 1. Sample preparation according to non-trimming method 
$\mathrm{mm}^{2}$ (Figure 1). The specimens were glued to an Instron machine with cyanoacrylate cement (Zapit Dental Ventures of America, Corona, CAl and then microtensile bond strengths to root canal dentin were measured. Bond strength data was expressed in MPa and statistical analysis was performed using a one-way analysis of variance, followed by multiple comparisons performed using a Duncan test at $5 \%$ level of significance.

\section{RESULTS}

The means and standard deviations of microtensile bond strength values for group are shown in Table 3. Statistically significant differences were found between the control group and Group $2(P<.05)$. The differences among the other groups were not significant (P>.05).

The tensile bond strength of CSE Bond to noncontaminated dentin (control) was 31.22 \pm 11.59 MPa. When the surface was contaminated with saliva after priming, the bond strength was reduced to 18.24 $12.21 \mathrm{MPa}$. This decrease between control and Group 2 was statistically significant $(P<.05)$. However there was no statistically significant difference among Group1 (control), Group 3 and Group $4(P<.05)$. When the fractured samples were evaluated with stereomicroscope, the fracture pattern was found to be mainly $(\% 80)$ adhesive.

\section{DISCUSSION}

Resin materials are considered to be susceptible to dentinal moisture contamination, which has been shown to adversely affect the bonding properties. ${ }^{13}$ Previous studies have shown that variation in dentin depth and permeability can also significantly influence the bond strength of direct restorative systems. ${ }^{14-16}$ In addition, the effects of the oral environment must be considered. The effects of bonding agents on saliva contaminated dentin have been evaluated in

Table 1. The materials and the ingredients of the materials with the application steps.

\begin{tabular}{|c|c|c|c|c|}
\hline Products & Material & Ingredients & Instructions & Manufacturer \\
\hline & Primer & $\begin{array}{l}\text { MDP, HEMA water, } \\
\text { initiator }\end{array}$ & Apply $20 \mathrm{~s}$ and dry & Kuraray \\
\hline Clearfil SE Bond & Adhesive & $\begin{array}{c}\text { MDP, HEMA, } \\
\text { dimethacrylates, initiator, } \\
\text { microfiller }\end{array}$ & Light cure $10 \mathrm{~s}$ & Medical Inc. \\
\hline Clearfil Photoposterior & Photoposterior & Hybrid, filler $85 \%$ & Light cure $40 \mathrm{~s}$ & Tokyo, Japan \\
\hline
\end{tabular}

Table 2. The ingredients of the artificial saliva.

\begin{tabular}{lcc} 
Artificial saliva & Concentration $(\mathrm{mmole} / \mathrm{L})$ & Concentration $(\mathrm{g} / \mathrm{L})$ \\
\hline $\mathrm{CaCl}_{2}$ & 0.7 & 0.103 \\
$\mathrm{MgCl}_{2} \cdot 6 \mathrm{H}_{2} \mathrm{O}$ & 0.1 & 0.019 \\
$\mathrm{KH}_{2} \mathrm{PO}_{4}$ & 4.0 & 0.544 \\
Sodium azide & 30.8 & 2.00 \\
$\mathrm{KCl}$ & 30.0 & 2.24 \\
$\mathrm{HEPES}$ buffer (acid) & 20.0 & 4.77 \\
\hline
\end{tabular}

Table 3. Mean values of tensile bond strength (MPa) of CSE Bond to control and contaminated pulp chamber dentin. (Values with the same letter are not significantly different, Duncan test, $\mathrm{P}<.05$ )

\begin{tabular}{lcc}
\hline Groups & N & Bond Strength Values (Mean \pm SD) \\
\hline Group 1 (control) & 13 & $31.22 \pm 11.59 \mathrm{a}$ \\
Group 2 (primer+contamine) & 13 & $18.24 \pm 12.21 \mathrm{~b}$ \\
Group 3 (uncured bond+contamine) & 13 & $23.48 \pm 7.66 \mathrm{ab}$ \\
Group 4 (cured bond+contamine) & 13 & $26.14 \pm 8.34 \mathrm{ab}$ \\
\hline
\end{tabular}


several researches who used shear bond strength test. 1,17-21 In this study, microtensile bond strength test was used with the advantage of producing multiple specimens at each tooth. ${ }^{22}$ Phrukkanon et $\mathrm{al}^{23}$ using a modification of the microtensile technique reported that there was little difference in resin-dentin bond strengths with location or in tensile vs shear testing.

During endodontic therapy, the cavity contamination in posterior region is more possible than anterior region. In some clinical cases it is hard to apply rubber dam appropriately. Contamination may occur and it is hard to decide which steps should be repeated. Self-etching primers used in this study were reported to be effective for obtaining good adhesion. ${ }^{24,25}$ They require the total treatment of enamel and dentin with self-etching primers ${ }^{26,27}$ and these systems have been reported to demonstrate excellent clinical performance and high retention rate in clinical situations. ${ }^{28}$ Although in previous studies, ${ }^{1,21,29}$ many researchers used one bottle adhesive systems during testing the effect of contamination on bond strength, in this study a self etching primer system was used. Fritz et al $^{1}$ used one bottle adhesive system and shear bond strength test. They applied the saliva on cured adhesive resin, rinsed, dried and re-bonded adhesive to dentin. They found lower shear bond strength than the group which was contaminated before curing the adhesive resin. In this study, a self-etching primer system was used and cured adhesive resin was contaminated with saliva, rinsed, dried and re-treated in Group 4. The mean bond strength values were not different from the control group and Group 4. This discrepancy may be due to different materials and methods used in this study.

Hitmi et al ${ }^{19}$ evaluated the influence of the duration of salivary contamination at different stages during the bonding procedures on shear bond strengths of three dentin adhesives. They found that self etching primer (LB2) was more tolerant to salivary contamination if the contamination occured before polymerization of the adhesive resin. In this study, the group contaminated after primer application (Group 2) showed lower bond strength values when compared to the groups contaminated before or after adhesive application (Groups 3 and 4).

Self etching primers are applied to the tooth surface to ensure maximum adhesion by improving monomer penetration into hydrophilic dentin substrate, and to improve wettability of the tooth surface by bonding agent. ${ }^{3}$ In this study, in Group 2 , which was contaminated with artificial saliva for $10 \mathrm{~s}$ after primer application, the bond strength was dramatically reduced. Air drying means that the water-filled collagen layer will collapse and prevent penetration of the adhesive into the exposed collagen meshwork and thus, formation of a sound hybrid layer. It seems that the presence of water in the interstices of the collagen mesh is the dominating factor. A hydrophilic monomer such as HEMA in the self-etch primer would be rinsed away with water easily from the demineralized dentin, which might result in collapse of the collagen when the dentin surface was air-dried after rinsing. ${ }^{10}$

In a previous study, ${ }^{30}$ operatively removal of the contaminated area and repeating the entire bonding procedure was recommended.

\section{CONCLUSIONS}

In this study, saliva contamination after primer application significantly reduced bond strength. Contamination of the uncured adhesive was not critical according to the results of this study. In principle, any kind of contamination of the bonding area should be avoided.

\section{REFERENCES}

1. Fritz UB, Finger WJ, Stean H. Salivary contamination during bonding procedures with a one-bottle adhesive system. Quintessence Int 1998;29:567-572.

2. Burrow MF, Takakura H, Nakajima M, Inai N, Tagami J, Takatsu T. The influence of age and depth of dentin on bonding. Dent Mater 1994;10:241-246.

3. Miyazaki M, Oshida Y, Onose H. Dentin bonding systems: Factors affecting bond strength. In "Advanced Adhesive Dentistry $3^{\text {rd }}$ International Kuraray symposium" Ed. by Tagami J, Toledano M, Prati C, 130-148, Cirimido, Italy; 1999.

4. Nikaido $T$, Kunzelmann $\mathrm{KH}$, Chen $\mathrm{H}$, Ogata $\mathrm{M}$, Harada $\mathrm{N}$, Yamaguchi S, Cox CF, Hickel R, Tagami J. Evaluation of thermal cycling and mechanical loading on bond strength of a self-etching primer system to dentin. Dent Mater 2002;18:269-275

5. Hormati AA, Fuller JL, Denehy GE. Effects of contamination and mechanical disturbance on the quality of acid-etched enamel. J Am Dent Assoc 1980;100:34-38. 
6. Thomson JL, Main C, Gillespie FC, Stephen KW. The effect of salivary contamination on fissure sealant-enamel bond strength. J Oral Rehabil 1981;8:11-18.

7. Silverstone LM, Hicks MJ, Featherstone MJ. Oral fluid contamination of etched enamel surfaces: an SEM study. J Am Dent Assoc 1985;110:329-332.

8. Swift EJ, Triolo PT. Bond strengths of Scotchbond Multipurpose to moist dentin and enamel. Am J Dent 1992;5:318320.

9. Xie J, Powers JM, McGuckin RS. In vitro bond strength of two adhesives to enamel and dentin under normal and contaminated conditions. Dent Mater 1993;9:295-299.

10. Hiraishi N, Kitasako Y, Nikaido T, Nomura S, Burrow MF, Tagami J. Effect of artificial saliva contamination on $\mathrm{pH}$ value change and dentin bond strength. Dent Mater 2003;19:429-434.

11. Eisenburger M, Hughes J, West NX, Shellis RP, Addy M. The use of ultrasonication to study remineralisation of eroded enamel. Caries Res 2001;35:61-66.

12. Shono Y, Ogawa T, Terashita M, Carvalho RM, Pashley EL, Pashley DH. Regional measurement of resin-dentin bonding as an array. J Dent Res 1999;78:699-705.

13. Nikaido T, Takada T, Sasafuchi Y, Takano Y, Satoh M, Tagami J. Clinical factors influencing dentin bonding In "ModernTtrends in Adhesive Dentistry Proceedings of the Adhesive Dentistry Forum 1998" Ed by Sano H, Uno S, Inoue S, 58-67, Dental material department, Medical products division, Kuraray Co, Ltd, Japan; 1998.

14. Prati C, Pashley DH, Montanari G. Hydrostatic intrapulpal pressure and bond strength of bonding systems. Dent Mater 1991;7:54-58.

15. Davidson CL, Abdalla Al, De Gee AJ. An investigation into the quantity of dentine bonding systems for accomplishing a durable bond. J Oral Rehabil 1993;29:291-300.

16. Nikaido T, Burrow MF, Tagami J, Takatsu T. Effect of pulpal pressure on adhesion of resin composite to dentin: Bovine serum versus saline. Quintessence Int 1995;26:221-226.

17. Johnson ME, Burgess JO, Hermesch CB, Buikema DJ. Saliva contamination of dentin bonding agents. Oper Dent 1994;19:205-210

18. El-Kalla IH, Garcia-Godoy F. Saliva contamination and bond strength of single-bottle adhesives to enamel and dentin. Am J Dent 1997;10:83-87.

19. Hitmi L, Attal JP, Degrange M. Influence of the time-point of salivary contamination on dentin shear bond strength of 3 dentin adhesive systems. J Adhes Dent 1999;1:219-232.

20. Gökçe K, Benderli Y, Büyükgökçesu S. Farklı çalıșma ortamlarında kompozit rezinlerin mineye baḡlanma kuvvetlerinin karșılaștırmalı olarak deḡerlendirilmesi. Ege
Diș Hek Fak Derg 2000;21:38-44.

21. Taskonak B, Sertgöz A. Shear bond strengths of saliva contaminated 'one-bottle' adhesives. J Oral Rehabil 2002;29:559-564.

22. Sano H, Shono T, Sonoda H, Takatsu T. Relationship between surface area for adhesion and tensile bond strength-evaluation of a microtensile bond test. Dent Mater 1994;10:236-240.

23. Phrukkanon S, Burrow MF, Tyas MJ. The effect of dentine location and tubule orientation on the bond strengths between resin and dentine. $J$ Dent 1999;27:265-274.

24. Watanabe LG, Marshall GW Jr, Marshall SJ. Dentin shear strength: effects of tubule orientation and intratooth location. Dent Mater 1996;12:109-115.

25. Chigira H, Yukitani W, Hasegawa T, Manabe A, Itoh K, Hayakawa T, Debari K, Wakumoto S, Hisamitsu H. Selfetching dentin primers containing phenyl-P. J Dent Res 1994;73:1088-1095.

26. Barkmeier WW, Los SA, Triolo PT Jr. Bond strengths and SEM evaluation of Clearfil Liner Bond 2. Am J Dent 1995;8:289-293.

27. Harada N, Nakajima M, Pereira PNR, Yamaguchi S, Ogata M\& Tagami J. Tensile bond strengths of a newly developed one-bottle self-etching resin bonding system to various dental substrates. Dentistry in Japan 2000;36:47-53.

28. Latta MA, Barkmeier WW, Triolo PT, Cavel WT, Blankenau RJ. One year clinical evaluation of the Clearfil Liner Bond 2 system. (abstract 1186) J Dent Res 1997;76.

29. Eiriksson SO, Pereira PN, Swift EJ Jr, Heymann HO, Sigurdsson A. Effects of saliva contamination on resinresin bond strength. Dent Mater 2004;20:37-44.

30. Hansen EK, Munksgaard EC. Saliva contamination vs. efficacy of dentin bonding agents. Dent Mater 1989;5:329333. 